\title{
Networks of Innovation and the Establishment of a Spatial Data Infrastructure in Brazil
}

\author{
Gilberto Câmara ${ }^{1}$, Frederico Fonseca ${ }^{2}$, Antonio Miguel Monteiro ${ }^{1}$, Harlan Onsrud ${ }^{3}$ \\ ${ }^{1}$ Image Processing Division, National Institute for Space Research \\ Av. dos Astronautas, 1758 - 12227-001 - São José dos Campos , SP, Brazil \\ gilberto, miguel edpi.inpe.br \\ ${ }^{2}$ College of Information Sciences and Technology - The Pennsylvania State University, \\ University Park, PA, USA \\ ffonsecalist.psu.edu \\ ${ }^{3}$ Department of Spatial Information Science and Engineering \\ University of Maine, Orono, ME 04469-5711, USA Maine \\ onsrudespatial.maine.edu
}

\begin{abstract}
Transitional economies with large geographical areas (such as Brazil, Russia, India, and China) represent both a challenge and an opportunity for the creation of spatial data infrastructures (SDI). Setting up an SDI in transitional economies is critically dependent on the diffusion of geographical information systems technology in public and private institutions. We use Rogers' diffusion of innovations model to study how GIS technology was introduced in a transitional economy (Brazil). Because GIS technology is non-neutral, we use Actor-Network Theory, to explain the roles and importance of each of the main actors in the Brazilian case. We conclude by discussing the policy choices for making the Brazilian SDI sustainable, including both the open access to data and the use of open software. The Brazilian experience points out that public policies focused on the organization of SDI in transitional economies in midsized and large countries should promote the growth of collaborative networks.
\end{abstract}

\section{Keywords}

Spatial data infrastructures, transitional economies, GIS, information technology. 


\section{INTRODUCTION}

Transitional economies with large geographical areas are both a challenge and an opportunity for spatial data infrastructures (SDI). A good example is the so-called BRIC countries (Brazil, Russia, India and China), which have large populations and research and development (R\&D) in geographic information systems (GIS). These countries face significant challenges in handling their natural resources, and SDIs can potentially play an important role in managing their territories. One of the key differences between SDI and more conventional information infrastructures (II) (for example, the Internet) is that users need to be knowledgeable to handle the techniques for spatial data handling and analysis. Databases for spatial information are much more complex to handle than conventional database management systems (Shekhar et al., 1999), and traditional statistical techniques do not capture important properties of spatial data (Anselin, 1989). Thus, the use of GIS technology needs specialized skills that require substantial investments in capacity building.

When approaching the idea of an SDI for a transitional economy, there are two competing perspectives. One approach is viewing SDI as an automated map distribution system. In this case, SDI implementation focuses on map production and distribution of existing sources on an "as-is" basis. The alternative is viewing SDI as an enabler for understanding space. In this case, an SDI does not only deliver maps, but disseminates spatial data with associated quality control, metadata information, and semantic descriptions. The SDI user is someone who is able to combine spatial data from different sources to produce new information for a study area. We argue that the second vision is the one where SDI can play an important role in the economic growth of developing nations. While it is important in the long term to provide users with efficient means to feed their own creations, such as digital maps or analysis results back into an overall SDI cataloging, archiving, search and retrieval system, the core of an SDI resides in its source data (Onsrud, Camara, Campbell, \& Chakravarthy, 2004).

SDI is most needed in developing nations as a support for decision-making. For example, planning a new hydroelectric power plant requires an assessment of its potential impacts on communities and the environment. This leads to a need for building different scenarios with quality spatial data and adequate spatial analysis techniques. Static map products are unsuitable for such analyses. Thus, SDI will only have an 
impact on developing countries if its potential users are knowledgeable about GIS technology. Although the question of how an emerging country, which does not have prior skills in GIS, may leapfrog into an SDI stage is relevant, it is not part of our main discussion in this paper. Our key focus is on how transitional economies with large territories and emerging or established GIS communities may promote the growth of collaborative networks that will support the creation of a sustainable SDI.

Based on the premise that "GIS predates and enables SDI", this paper examines the adoption of GIS and SDI in Brazil beginning in 1984. Our theoretical basis is Rogers' diffusion of innovations model (Rogers, 1995), which has also been applied to the study of GIS and SDI technology (for example, Chan \& Williamson, 1999; Masser, 2005; for example, Nedovic-Budic, 1998). We identify a set of leading institutions (early adopters in Rogers' terminology) which have played an important role in pioneering GIS and SDI technologies in Brazil. We also point to the links between these early adopters, and their impact in promoting GIS/SDI technologies. We complement our Rogers' inspired analysis of the Brazilian SDI implementation, with the use of Actor-Network Theory (Latour, 1988; Law, 1992) to suggest some alternative perspectives to the problem.

Our hypothesis is that Brazil has been successful in its SDI development so far largely due to a set of early adopters that combined R\&D in spatial information with producing and disseminating spatial data. We have labeled the early adopters of GIS and SDI in Brazil as the "network of innovators". This collaborative network was instrumental to ensure that such a large country could benefit from spatial information technologies. The network was successful because it combined expertise in different areas of spatial information technology. These early adopters viewed knowledge as a public consumption good (Dasgupta \& David, 1994) and openly spread their experience and their results. Our claims are consistent with the literature on economics of science and technology which argues that economic returns of scientific projects are difficult to measure directly (Dasgupta \& David, 1994; David, Mowery, \& Steinmueller, 1992; Nelson, 1996; Ruttan, 2001). Therefore, investigators on R\&D innovation prefer to stress the linkages between research and the market. As David et al. (1992) argue: "The number and richness of links between the knowledge generated by basic scientific projects... are important determinants of the potential economic returns". 
We will also discuss how the early adopters of GIS in Brazil have helped to avoid the "lock-in" effects associated with the introduction of information technologies in transitional economies (Arthur, 1994) (Mowery, 1996). The "lock-in" effect is relevant in GIS software, where two companies (ESRI® and Intergraph $\left.{ }^{\circledR}\right)$ hold about $50 \%$ of the world's market (Daratech, 2003). In Brazil, associating public diffusion of innovation with locally developed no-cost and open source software enabled many institutions to avoid being locked-in to a particular vendor's solution. For instance, an indicator of the reduction on the "lock-in" effect is the fact that companies offering services based on open source software form $15 \%$ of the service provider market (Magalhaes \& Granemman, 2005).

In what follows, we will first apply Rogers' model of diffusion of innovations to understand GIS and SDI diffusion. In section 3, we give a brief introduction to three of the main players in the Brazilian SDI. Then, we will apply Rogers' model to the analysis of the Brazilian case, including how the network of innovators influenced adoption of GIS and SDI in Brazil. We point to challenges and tensions that currently remain before Brazil can fully complete a nationwide SDI. Finally, we consider how the lessons from the Brazilian case can be useful to other developing countries.

\section{DIFFUSION OF INNOVATIONS IN GIS AND SDI}

The diffusion of innovations model was originally articulated by Everett Rogers (1995) and explored in various subsequent research studies (Chan \& Williamson, 1999; Grubler, 1998; Masser, 2005; Nedovic-Budic, 1998; Ruttan, 2001). This model proposes that the rate of adoption of an innovation follows an equation similar to the spreading of an epidemic disease. The cumulative number of adopters of a new technology follows a logistic ( $S$-shaped) curve and therefore, the number of adopters over time follows a normal distribution (see Figure 1). Rogers identified five categories of technology adopters: (1) Innovators, who outbound their local circle of peer networks towards more cosmopolite social relationships; (2) Early adopters, who are closer to the local social system than innovators; (3) Early majority, who embrace innovation just before the average member does; (4) Late majority, who adopts new ideas just after the average members; and (5) Laggards, who are the last to adopt innovation. 
Rogers considers that rate of adoption of an innovation depends on the adopters' perception of the following five characteristics of the innovation: (1) relative advantage, (2) compatibility, (3) complexity, (4) trialability, and (5) observability. To apply Rogers' model to spatial information technology, we first need to understand the qualities of GIS and SDI as innovative technologies. The diffusion of the innovation represents an immaterial entity that spreads like an epidemic, and is neutral in relation to its adopters. Rogers' view assumes adopters can be objective when comparing current practices to new ones. Ruttan's (2001) following comment emphasizes the strength of Rogers' analysis: "The S-shaped logistic curve has remained remarkably robust as a description of the technology diffusion and the substitution processes" (p.171).

Diffusion theory is not the only explanation for innovation. Other theories, such as Actor-Network Theory (Latour, 1988), consider that objective judgment is difficult to achieve in practice. To assess an innovation, would-be adopters need to associate the innovation with their own experiences and worldviews. Actor-network theory discards the view of innovation as a neutral entity, but as constituted as heterogeneous networks that come together due to various translations, including political. Technology only makes sense when used by an 'actor' with interests and roles, thus translation is argued by Actor-network theorists as a more relevant conceptual mechanism than diffusion for the adoption of new technologies. What gives meaning to the technologies are the way in which actors translate themselves with the worldviews of others and the way they preserve or confront the status quo (McMaster, Vidgen, \& Wastell, 1997).

Therefore, diffusion and translation approaches may provide alternative views of GIS technology adoption on transitional economies. Diffusion will further the understanding of the network aspects of the Brazilian SDI while Actor-Network Theory will explain the roles and importance of each of the main actors in the Brazilian case. We have chosen to discuss first the problem from a diffusion perspective, since our primary focus is on how technically minded institutions influence the introduction of GIS technology in transitional economies. Also, our analysis is more at the macro level of the institutions rather than at the micro level of particular projects, to which an ActorNetwork Theory analysis is more amenable to. We recognize that GIS technology is non-neutral, making translation-based analysis approaches (such as Actor-Network 
Theory, Latour, 1988) potentially able to provide interesting insights to the analysis. We present this complementary view to our discussion towards the end of the paper.

\section{A NETWORK OF EARLY-ADOPTERS: THE BRAZILIAN SDI}

Among the many participants in the development of the Brazilian SDI, we chose to focus on three key ones, originating from three different sectors of the economy with varying missions. The first, INPE, is a major research institute funded by the federal government. The second, Prodabel, is a information technology company owned by a local government which has one of the most successful urban GIS projects in Brazil (Borges \& Sahay, 2000). And finally, Fator-GIS and its spin-off Mundo-Geo which are, today, the most important media companies with interests in GIS in Brazil. Each actor represents an important facet in the development of a SDI. INPE brings in a strong research and technology group. Prodabel is application-driven, a good place to apply the research and technology developed at INPE. Fator-GIS acts as a place where these two worlds could meet and share their GIS experiences between them and among other kinds of users.

During the $80 \mathrm{~s}$, aiming at the protection of the local information technology industry, the Brazilian Government adopted a "market reserve" policy. For eight years, there was a heavy economic incentive provided by the government to produce local information technology (IT) hardware goods. The 'market reserve' law provided a powerful incentive for local development of GIS and Remote Sensing Image Processing technology. By then, the average price for a single-seat system was approximately US\$ 100,000, including hardware, software and training costs. As a result, INPE established its Image Processing Division in 1984 with the following aims: (a) local development and dissemination of image processing and GIS systems in Brazil; (b) establishment of a research program in Image Processing and GIS, and (c) pursuit of co-operative programs with universities, government organizations and private companies. In 1986, INPE brought out Brazil's first GIS based on an Intel platform, which was used extensively by 150 universities and research labs up to 1996.

In 1992, given recent advances in hardware and software and the changes in information technology policy in Brazil, INPE started the development of a free GIS software, SPRING, whose first Internet version was made available in late 1996. 
SPRING provides a comprehensive set of functions for processing of spatial information, including tools for Satellite Image Processing, Digital Terrain Modeling, Spatial Analysis, Geostatistics, Spatial Statistics, Spatial Databases and Map Management. Currently, in a partnership with Computer Graphics Group at the Catholic University in Rio de Janeiro, INPE is developing TerraLib (Gilberto Câmara et al., 2000), an open-source GIS component library. TerraLib enables quick development of custom-built applications using spatial databases (see www.terralib.org for further details).

The second player is Prodabel, Belo Horizonte's IT company. Belo Horizonte is the fourth largest Brazilian city, with a population of more than 2.2 million people, spread over 335 square kilometers, and is the center of a metropolitan area that houses over 3.5 million people. Belo Horizonte's GIS project which started in 1989 was managed by Prodabel. An interesting fact was that Prodabel also hosted the city's cartography. The main efforts were towards creating the geographic database, the development of the necessary human resources, and the search for partnerships within the city. In the long run, the project became a reference for urban GIS in Brazil. Its team grew out to be participating in the local government activities and today play a major role in the Brazilian scientific community. The project architecture started with a centralized effort and later moved to a decentralized service structure. The GIS project for the city of Belo Horizonte has received national and international recognition for providing applications that deal with important social needs, including education, health, transportation, traffic and environmental control. The results also include over 200 publications, including theses, academic papers and articles in trade magazines, written by PRODABEL researchers (Borges \& Sahay, 2000; Davis Jr., 1993; Fonseca, 1993). .

A third player is Fator-GIS, a media company that started out in 1993 publishing a small magazine on GIS. From the magazine, Factor-GIS started a very successful userconference series called GIS-Brasil, holding annual meetings till 2004. The company went through some changes in 1999 which led to an online publication replacing the original paper magazine. It generated also a spin-off called MundoGeo which has a portal, a paper magazine, and its own user-conference series, Geo-Brasil, which has been held annually since 2000 . 
We will discuss how these players found each other and interacted to create a successful SDI network in Brazil. Other important players in this process will be mentioned later. Brazil's path towards a SDI can be summarized in Table 1. There we can see the first GIS software release by INPE in 1986, the first scientific conference in 1990, and the first user conference in 1994. We can also see that after 1997 all these activities were established as permanent events in contrast with their temporary and sparse presence before 1994.

Table 1 - a chronological summary of the main events in the establishment of the Brazilian SDI

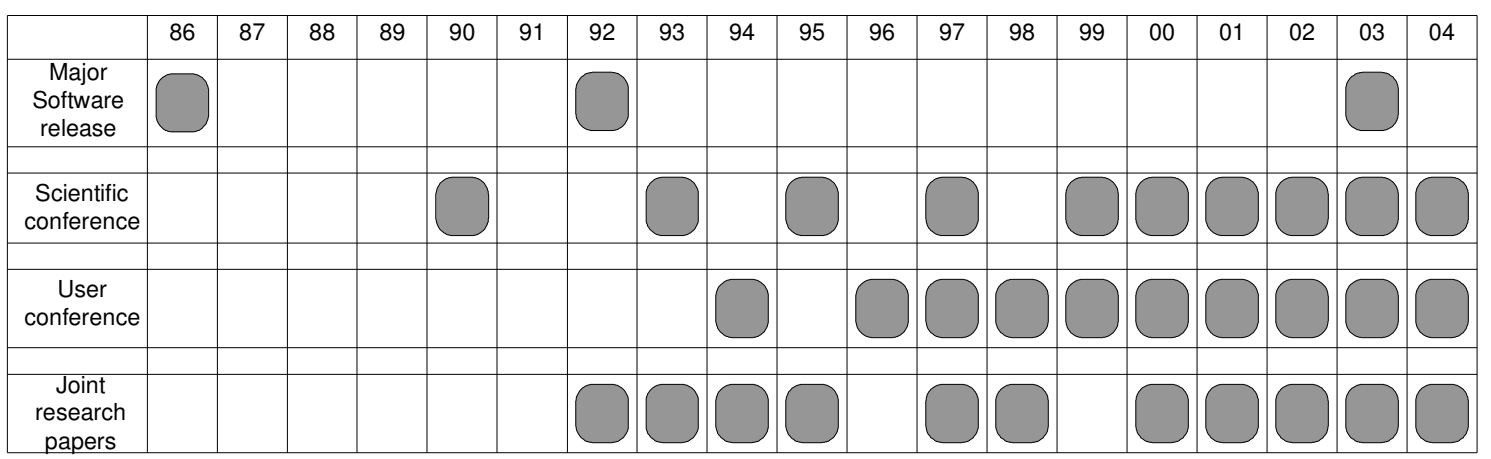

\section{EVIDENCES OF SDI ESTABLISHMENT IN BRAZIL}

To assess the applicability of Rogers' diffusion of innovation model to the SDI case in Brazil, we have used the number of registered users of the SPRING Brazilian GIS software (Figure 1). SPRING integrates spatial analysis, map algebra, digital terrain modeling and image processing and has been available on the Internet since November 1996 (Gilberto Câmara, Souza, Freitas, \& Garrido, 1996). The number of new registered users of SPRING in Brazil follows roughly a bell-shaped curve, a trajectory that is consistent with Rogers' diffusion model. Starting from 500 registered users in 1997, there was a peak of 7,800 new users in 2002, before declining to 6,300 in 2003 and 5,200 in 2004. We consider that the cumulative number of SPRING users provides an assessment of the extent of the diffusion of GIS in Brazil. We take the years 19861994 as the "early adopter" period and the years 1994-2004 as the "early majority" period. The country is now entering Rogers' fourth period, that of the "late majority". This phasing is of course the result of our interpretive analysis, rather than an objective peridiodization of events. 


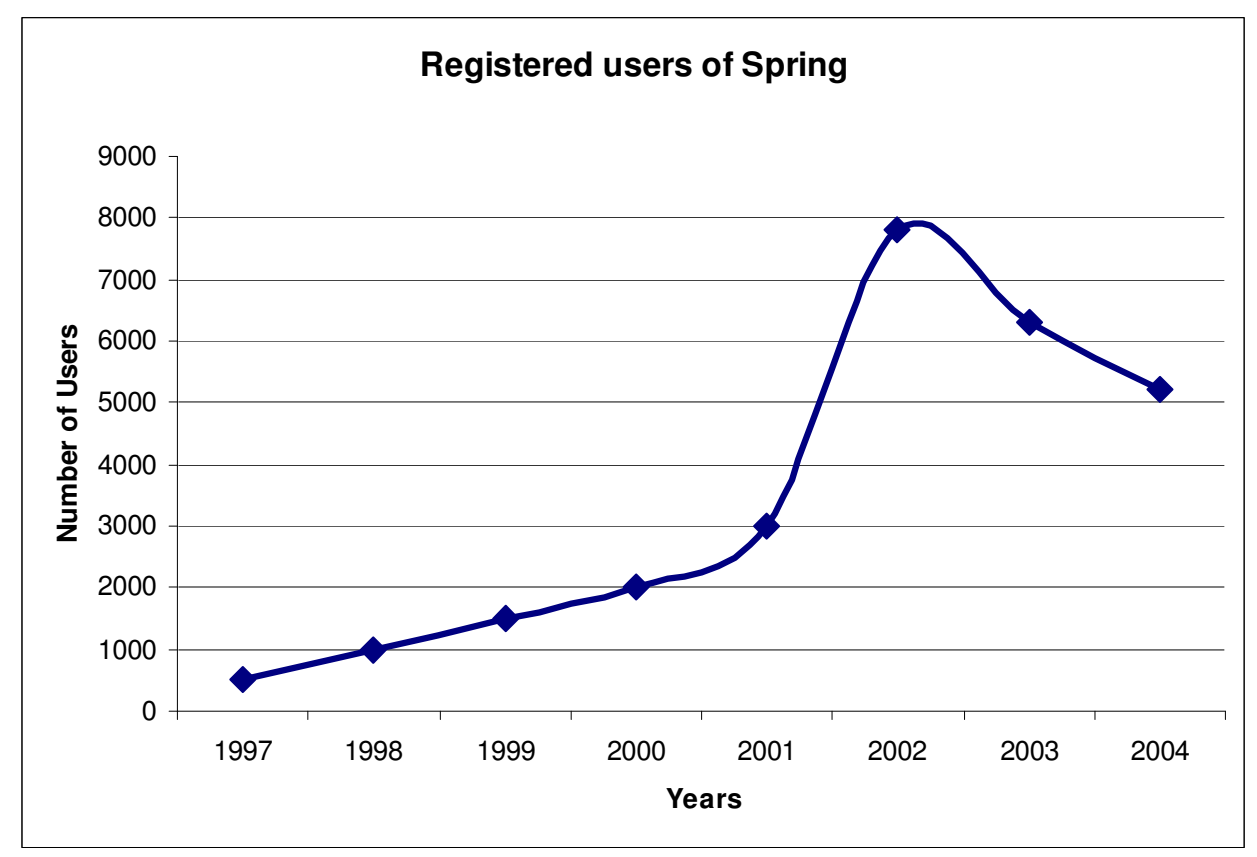

Figure 1 - Evolution of new users of SPRING in Brazil (1997-2004). Source: INPE

Adaptation of GIS software and support to meet the needs of transitional economies may help explain why SPRING has spread at a more rapid rate of adoption and reached a larger portion of the population of potential users in Brazil than most commercial alternatives. For instance, in the 90s, more than 2,000 students attended short courses on SPRING and GIS and 27,300 copies of Spring were download from 1997 to 2004. For some adopters, SPRING was replacing commercial GIS to carry out the same tasks at a far less cost. It had the relative advantage of needing minimal capital investment for software, or its support or maintenance fees, and free technical support in Portuguese. In addition, switching to SPRING conferred the relative advantage of increased prestige by using locally developed software. SPRING also had the advantage of being more compatible with the language and culture of Brazil. The software interface and documentation are in Portuguese, and software availability was coupled with extensive investments done by INPE on training material and capacity building. To reduce the complexity of GIS adoption to the average user, INPE researchers (with other network members) produced a three-volume reference work on GIS: "Introduction to GIS", "Spatial Analysis" and "Spatial Databases," which was made freely available on the Web. This material has been instrumental in promoting the use of SPRING in Brazil by GIS students, government officials, and private companies. SPRING is also a 
basic GIS tool for students in undergraduate and graduate courses in GIS in many universities in Brazil.

\section{THE NETWORK OF INNOVATION FOR GIS AND SDI IN BRAZIL}

This section explores the role played by the actors in a collaborative network. First we identify who were the early adopters in setting up GIS/SDI in Brazil. Then, we identify the linkages between these early adopters and point out how they supported new GIS/SDI groups, including the role of the private companies. Although there are other relevant relationships, we opted to focus only on the relations of INPE with other institutions.

\subsection{Collaboration between early-adopters of GIS technology in Brazil}

We categorize the "early adoption" period of GIS in Brazil to span from 1986, when INPE released its first GIS software, to 1994 when Fator-GIS promoted the first major user conference. We have selected some institutions that, in this period, played a significant role in fostering adoption of spatial information technology, as shown in Table 2.

Table 2 - some of the early adopters of GIS in Brazil

\begin{tabular}{|l|l|l|l|l|}
\hline \multicolumn{1}{|c|}{ Institution } & \multicolumn{1}{|c|}{ Main line of business } & \multicolumn{1}{c|}{ Funded by } & \multicolumn{1}{c|}{$\begin{array}{c}\text { First } \\
\text { main } \\
\text { initiative } \\
\text { in GIS }\end{array}$} \\
\hline $\mathbf{1}$ & INPE & Research Institute & Government & 1984 \\
\hline $\mathbf{2}$ & UNICAMP & University & Government & 1993 \\
\hline $\mathbf{3}$ & Prodabel & IT services & Government & 1989 \\
\hline $\mathbf{4}$ & EMBRAPA & Research Institute & Government & 1989 \\
\hline $\mathbf{5}$ & TECGRAF & Academic Research Laboratory & Private & 1987 \\
\hline $\mathbf{6}$ & Fator-GIS & Media company & Private & 1993 \\
\hline
\end{tabular}


The early adopters worked together in many projects and thus created significant links, which were fundamental for the successful implementation of an SDI in Brazil. For instance, from 1994 to 1997, UNICAMP led a multi-million dollar cooperative project in Geoinformatics with INPE, CPqD, EMBRAPA, and PUC-Rio (Gilberto Câmara, Casanova, Hemerly, Magalhães, \& Bauzer-Medeiros, 1996; Gilberto Câmara et al., 1994). EMBRAPA has developed joint work with INPE focusing on spatial analysis and modeling applied to agriculture (Assad \& Sano, 1998) and with UNICAMP focusing on interoperability and semantics (Fileto, Medeiros, Liu, Pu, \& Assad, 2003). We can see in Figure 2 some examples of the relationships of INPE with other members in the network.
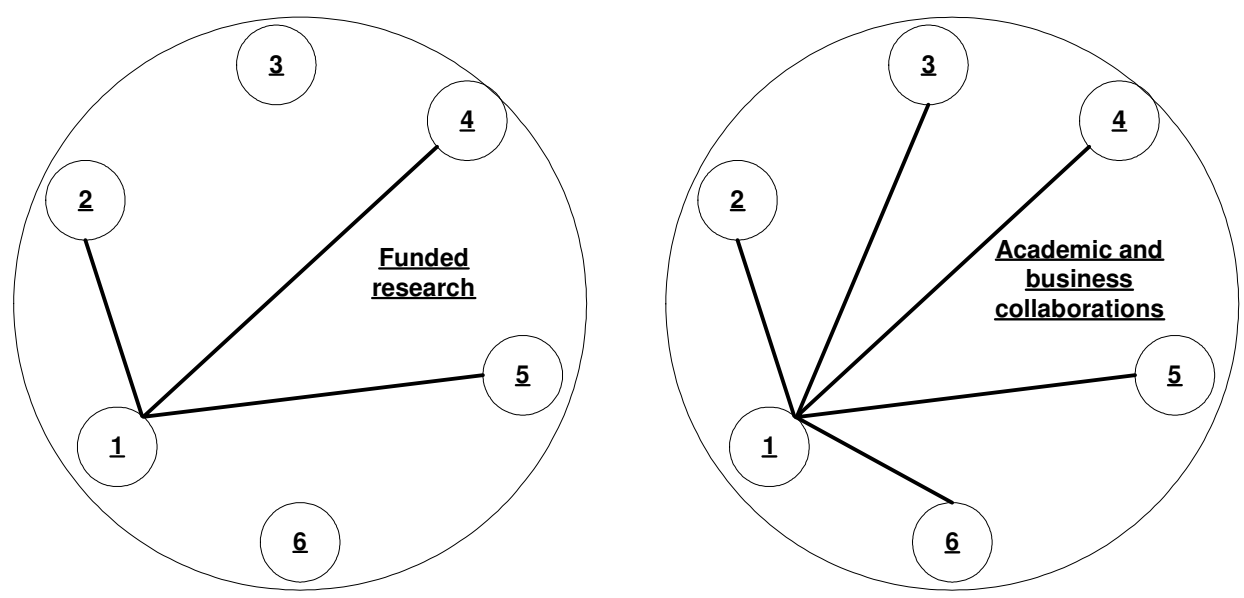

Figure 2 - relations between INPE and other players

As a measure of linkages between the various R\&D groups, Figure 3 shows the fully refereed papers and book chapters published by the INPE GIS group in the period 19902005. The papers were divided into those whose authors are only from INPE, and those co-authored with researchers from other institutions. There is a clear trend towards the increase of collaborative papers in recent years, reflecting a strengthening of links with other R\&D groups. 


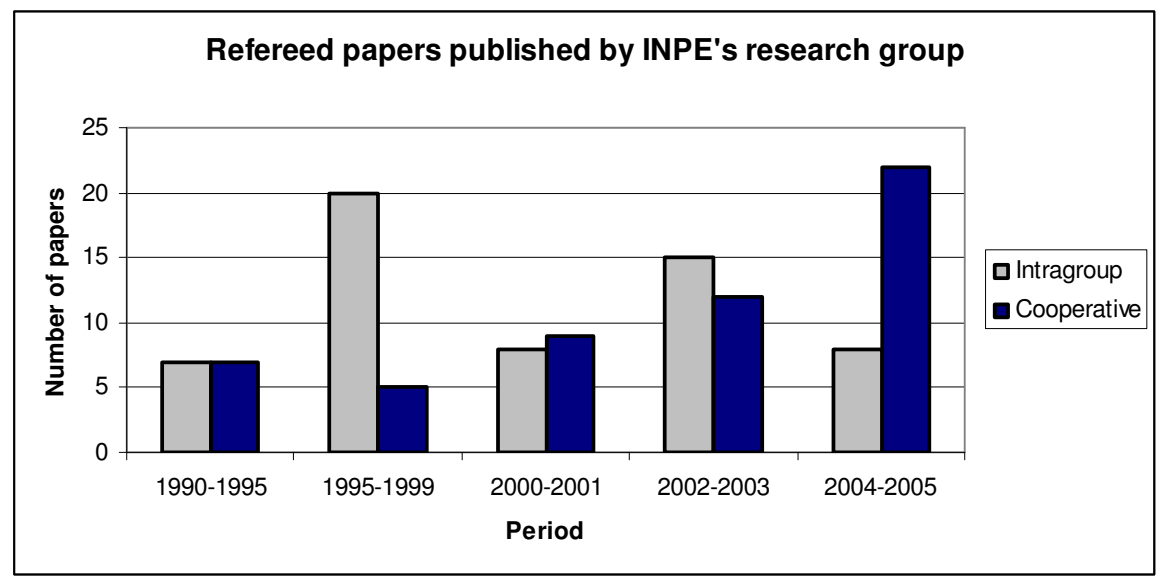

Figure 3 - collaboration between INPE and other players in scientific papers published in geoinformation technology (1990-2005). Source: INPE

In a qualitative sense, the early production of referred papers by INPE described different aspects of the implementation of GIS systems (Gilberto Câmara et al., 1996). As the R\&D team matured, it felt the need to focus on science, including: (a) environmental modeling, especially land-use changes models in Amazonia (Gilberto Câmara et al., 2005); (b) interoperability and semantics of spatial data (Fonseca, Davis, \& Camara, 2003; Fonseca, Egenhofer, Agouris, \& Câmara, 2002); (c) spatial analysis applied to socioeconomic issues (Gilberto Câmara et al., 2004). This scientific production was supported by international cooperation, as described later in the paper.

One of strategies adopted by the early adopters was to support initiatives for interaction with other groups interested in GIS in Brazil. The adopters had an active role in pursing partnerships with groups in various disciplines that had an interest in spatial technologies. These included research groups in different areas: (a) spatial epidemiology in partnership with the National School for Public Health; (b) social exclusion in partnership with the Catholic University of São Paulo; (c) crime analysis in partnership with the Federal University of Belo Horizonte. These and other research groups used GIS for their applications, and this resulted in an increase in cooperative papers as shown in Figure 3.

A second important strategy of INPE was not to base the technological implementation on cloning existing software. One of important challenges in the use of GIS in developing nations with large geographical area is the lack of updated maps. For this reason, remote sensing imagery is an essential component of most geospatial applications. For this reason, the design of the SPRING system (done in 1991) was 
based on integrated remote sensing and GIS with an object-oriented data model (Gilberto Câmara et al., 1996). At the time, the concepts of object-oriented modeling were new in GIS, and the part of the success of SPRING can be traced to its use of what was then an innovative technology.

\subsection{The role of the private companies}

Assessment of the role played by the private companies in diffusion of innovations is a major challenge in transitional economies. The case of GIS/SDI Brazil is no different. The available surveys are still incomplete and give only rough indicators of the extent of this participation. According to a recent survey (Magalhaes \& Granemman, 2005), there are more than 200 companies working with GIS in Brazil. The total market is estimated in around US\$ 150 million, and employee numbers are over 4,000, more than $75 \%$ of them with a technical background. Agriculture and facilities management are the largest private application markets; urban cadastre makes up $45 \%$ of the public customers (Magalhaes \& Granemman, 2005). Companies offering services based on open source software form $15 \%$ of the service provider market. This is an indicator of a reduction on the "lock-in" effect, further discussed in the next section. To discuss the linkages between the various actors in the networks of innovation and the private companies, we will consider three cases: (a) data providers; (b) service providers based on commercial software; and, (c) service providers based on open source software.

The data providers have settled their business around the failures of the Brazilian mapping agencies to provide basic digital cartographic information. Mostly, their business consisted of digitizing existing topographic maps, as well as high-resolution imagery distribution. The business of data provision will soon change significantly. As a more comprehensive SDI is established, and public maps are made available in digital formats, the data providers will have to change their business models. Either they have to adopt new technology such as digital photogrammetry for creating new maps, or they will have to become service providers of location based services and online maps.

The service providers based on commercial software have based their strategy on the leverage provided by existing proprietary solutions. Usually, they associate software licensing to services such as customization and database modeling. This model has proven successful. However, it is subject to the same transitions that are happening in 
the international GIS arena, where a new generation of spatial databases is already having a strong impact on the market. These companies are struggling to adapt themselves to these changes, including staffing of their technical team, where instead of mostly hiring cartographers and geographers for map making activities, they require experts in spatial databases. These experts should know how to take advantage of the increased availability of data as a national SDI is established. The "early adopters" are the main providers of qualified personnel for these companies.

We foresee that in the coming years the private companies will continue to be strongly influenced by the networks of innovators. As the public SDI in Brazil grows, we can expect a reduced market for data providers and an expansion of the market for service providers. The service providers will have to adapt themselves to a geospatial information market centered around building corporate applications based on spatial databases. This will increase the influence of the "early adopters" who are in a privileged position to understand the future of spatial information technology.

\subsection{The role of international collaboration}

In the Brazilian case, an important benefit resulting from the development of local technology has been a very complete understanding of the "core" aspects of GIS technology. As a sub product of this understanding came a capacity, by involved staff, to dissect the proprietary commercial solutions in order to know their strengths and weaknesses. In this respect, this is the result of a "learning-by-doing" process. Such processes, as opposed to "learning-by-using", are credited with fostering innovation in the developed world (Landes, 1999) and similar lessons would appear to apply for those nations supporting emerging economies. Learning by doing and creating requires substantial local investment in human resources. This local investment is benefiting substantially from scientific ties with leading centers of GIS and Remote Sensing research in the USA and Europe. Some of these linkages include: (a) The Department of Spatial Information Science and Engineering at the University of Maine; (b) The Department of Geography at the University of California at Santa Barbara; (c) The School of Information Sciences and Technology at Penn State University; (d) The Institute for Geoinformation and Cartography at the Technical University of Vienna; (e) The Institute for Geoinformatics at University of Munster, Germany; (f) The University of Wageningen, Netherlands. 
International collaboration has provided the GIS groups in Brazil with exposure to research questions that will influence the future of the technology. In so doing, GIS developers in transitional economics are able to increase the cycle of innovation of their products and even anticipate some of the innovations in the market. For instance, in 1990 Max Egenhofer from the University of Maine, USA, visited Brazil and presented a lecture on "Object-Oriented modeling for GIS" (Egenhofer \& Frank, 1989). His talk influenced the design of SPRING (Gilberto Câmara et al., 1996), which anticipated by almost a decade the use of object-oriented modeling in commercial GIS software.

\section{MOVING FROM GIS TO SDI IN BRAZIL: CHALLENGES AND POSSIBILITIES}

\subsection{Sustainability of GIS/SDI in Brazil: the role of users}

GIS is considered a disruptive technology. Such technologies are new technologies that require important organizational changes. They usually need specialists and managers whose knowledge is very different from the those of the technology it displaces. This is clearly the case of GIS, when manual map-makers are replaced by geographical database specialists. Disruptive technologies, such as GIS, are usually actively promoted by software developers and service vendors. Such "push-oriented" actions are not matched by the ability of users to adapt to the technological change (Ramasubramanian, 1999; Sahay \& Walsham, 1996). In Brazil, most of the "early adopters" were both users and developers. Institutions such as INPE and PRODABEL are large users of spatial technologies and were involved in the full circle of conception, development, use and maintenance of GIS.

One example shows how acquiring GIS technology was motivated by user demands. INPE had operated a LANDSAT remote sensing ground station since 1974 and had established a remote sensing application group since 1975. There was a perceived need for appropriate technology for image processing and GIS that could be used in applications of natural resources management. These needs mandated the creation, in 1984, of an R\&D group in image processing to produce technology that was closely linked to users' needs. Development and acquisition of technology at INPE, which culminated in 100,000 satellite images being delivered during 2005, was successful and sustainable because it was all the time "pull-oriented" rather than "push-oriented". 


\subsection{Paradoxes and tensions in GIS/SDI establishment in Brazil}

Although this paper reports a successful story on the establishment of GIS/SDI in Brazil, there are still many unresolved issues before SDI can be fully implemented in Brazil. The move towards a nationwide SDI in Brazil has been led by the network of innovators including INPE, Prodabel, Fator GIS and others. They recognized the importance of dealing with spatial information as a fundamental part of information infrastructure, and not as a collection of digital maps. Meanwhile, the civilian mapping agency (IBGE) and the military mapping agency (DSG) continue to deal with customers by providing most of their data as paper maps. These mapping agencies neglect the users' capacity for using spatial data to do their own analysis. Even when topographical digital data is made available, it is delivered in formats that are problematic. For instance, digital terrain models are delivered as contour lines instead of grids and with no associated metadata.

The contrast between the practices of the innovators and the mapping agencies has led to a strained relation between the two groups. This tension is an impediment for a successful nationwide SDI since users need data from the mapping agencies. As a result, many independent data providers have set up a commercial business of selling digitized public maps. The contrasting policies and world-views have also blocked a national consensus around a nationwide SDI infrastructure. In result, Brazil has currently no legislation on access policies for public spatial data sets.

As signaled in the paper, the innovators were strongly associated with research and development initiatives. As the user base of GIS/SDI expands in the country, new users are likely to have a more application-oriented profile. Increasing demand for highquality spatial data is likely to force all actors to clearly establish their data policies. There will be a strong debate between the mapping agencies and the innovators about which model to adopt nationally. We hope the good results obtained by innovators will serve as basis for establishing an open nationwide spatial data policy.

In the long run, SDI in developing countries may be facing a dilemma between having good data commercially available but out of reach of a major part of the users or free data but with low quality. Solving the possible dilemma requires a new generation of researchers and practitioners in the field. Since the network of innovators of GIS/SDI in Brazil has viewed knowledge as a public consumption good and has stressed capacity 
building, we believe their view will prevail. For instance, from May 2004 to May 2005, the National Institute for Space Research (INPE) delivered more than 100,000 CBERS2 CCD images, which are available free to Brazilian users through the Internet. CBERS2 is the second of a series of five remote sensing satellites being developed in cooperation between China and Brazil on the period 1988-2011. Each image covers 120 x $120 \mathrm{~km} 2$ at $20 \mathrm{~m}$ resolution, in spectral bands (2 visible, 1 near-infrared) with $100 \mathrm{Mb}$ size. These numbers make Brazil the world's largest distributor of remote sensing imagery.

\subsection{Avoiding the lock-in effect: the road to open source SDI}

One of the main concerns in SDI establishment in transitional economies is the issue of avoiding the "lock-in" effect in the choice of technology (Arthur, 1994). This effect is well-known in the software industry since the customer may become dependent on proprietary data formats or interfaces, and high switching costs might prevent the change to another product (Ruttan, 2001). Substantial barriers to entry are created, resulting in effective monopolies. The GIS software market is an oligopoly in which two companies (ESRI ${ }^{\circledR}$ and Intergraph ${ }^{\circledR}$ ) have a market share of 50\% (Daratech, 2003).

In Brazil, the "lock-in" effect was reduced because of several reasons. During the 80 s and 90s, locally developed technology could, often, provide an alternative to commercial vendors. In the 80s, INPE developed an Intel GIS at the same time ESRI launched an equivalent product. In the early 90s, PRODABEL and others chose alternative solutions to the mainstream vendors and were successful in their choices. In the same period, INPE's SPRING software provided tight integration of GIS and image processing functions, which is necessary for natural resources applications (Gilberto Câmara et al., 1996). The network of innovators created a culture of "digital brains" that understood the basic principles of GIS, and forged a generation of developers that was not locked in to the main vendors. In this decade, this new generation could benefit from the emergence of open source GIS to produce solutions that match user needs and avoid proprietary technology.

For SDI, low-cost or open source software is crucial (Holmes, Doyle, \& Wilson, 2005). As outlined by Câmara et al. (2000), GIS software development is changing. 
Coupled with advances in database management systems, rapid application development environments enable building "vertically integrated" solutions tailored to the users' needs. Therefore, an important challenge for the GIS/SDI community is finding ways of taking advantage of the new generation of spatially enabled database systems to build "faster, cheaper, smaller" GIS/SDI technology.

Open source GIS software such as PostGIS, MapServer and TerraLib (Holmes et al., 2005) can provide an effective technological base to develop SDI that are independent of proprietary technology. GIS open source software tools allow researchers and solution providers to access a wide range of tools than what is currently offered by the commercial companies. In Brazil, the network of innovators is moving towards open source software. PRODABEL and others have been active in promoting OGC standards (Casanova, Camara, Davis, Vinhas, \& Queiroz, 2005). PUC-Rio and INPE are the main developers of the TerraLib open source library (Gilberto Câmara et al., 2000). As a result, many important SDI providers in Brazil are not currently locked into proprietary GIS technologies, and can afford to move directly to open source solutions.

\section{LESSONS LEARNED FROM THE BRAZILIAN GIS/SDI EXPERIENCE}

The Brazilian experience provides wider implications for other developing (and developed) countries on how to approach the SDI implementation challenge. In this section, we identify some general principles that we have learned from the experience of the network of GIS/SDI innovation in Brazil, and discuss to what extent these principles can be applicable elsewhere.

\subsection{Extending the Brazilian experience to other countries}

Our lessons are mostly applicable to countries with large territories and GIS R\&D communities, such as the BRIC countries (Brazil, Russia, India and China), and to countries with medium-size territories and emerging GIS R\&D communities, such as Mexico, Egypt, and South Africa. In contrast to some of these countries, Brazil does not have a tradition of a strong centralized government. As a result, there was no one decision to entrust national mapping agencies with the task of setting up a nationwide SDI. As a result, institutions without a strong mapping culture but with a deep understanding of information technology played a significant role in diffusing GIS/SDI 
culture in Brazil. GIS worked effectively in Brazil only because its innovators worked "outside the system", and the contribution of the mapping agencies was limited.

The experience reported in the paper is consistent with the innovation literature, which points out that it is difficult for breakthroughs to occur inside large organizations. An often-cited example is the case of the IBM PC (Ruttan, 2001). IBM's internal resistance to the new technology enabled a start-up such as Microsoft to dominate the personal computer software market (Gates, Myhrvold, \& Rinearson, 1996). The Brazilian experience points out that transitional economies willing to succeed on SDI technologies should support institutions that are intellectually independent of the mapproduction mind-set. We argue the core of these institutions should be people with "digital brains", which are fully aware of the possibilities offered by the digital world. By starting anew and giving the newcomers a mandate for change, these countries are more likely to succeed in setting up a nationwide SDI.

\subsection{An alternative theoretical examination of the Brazilian experience}

Although we mainly used Rogers' innovation theory to examine the Brazilian experience, some aspects of the Brazilian SDI may be better explained by alternative theories. In this section we use some of the concepts from the Actor-Network theory (Latour, 1988; Law, 1992) to understand how the Brazilian SDI survived through some of the challenges it has faced. The main actor identified is Fator-GIS, a seemingly minor actor and with objectives that at first would seem to be at odds with the other actors. Factor-GIS would seem at first to be only a commercial GIS magazine. Nevertheless, this was not the case. In the Brazilian network, Fator-GIS provided the forum where rich interactions among other actors could happen and helped establish a successful network. Without the forum created by Fator-GIS, the interactions among the actors could have been delayed or never happened. Therefore, the organization of a series of user conferences made Fator-GIS a strategic participant in the network because of its role as a catalyst.

The first concept that is useful for our analysis is the heterogeneous network, which "is a way of suggesting that society, organisations, agents and machines are all effects generated in patterned networks of diverse (not simply human) materials." (Law, 1992). One of the peculiarities of the Brazilian SDI was that three different sectors worked 
together. INPE is a mainly a research institute while Prodabel is a service company and the third main actor here, Fator-GIS, is a privately owned company. It was in the userconference series promoted by Fator-GIS that the other two could establish and nourish their relationships which later proved so fruitful. Here the different objectives of each company, instead of playing out as a hindrance, came about as being synergetic. Prodabel could learn and enhance its research capacities from INPE. INPE could learn the practical side of the trade and expanded SPRING in the direction of urban GIS. People from both INPE and Prodabel gave presentations, courses, and wrote articles in Factor-GIS' outlets. So while Factor-GIS was attending their business interests, it was also helping out INPE and Prodabel to present their capacities to a larger audience and gather more participants to the network.

Another fundamental concept in Actor-Network theory is translation, which "implies transformation and the possibility of equivalence, the possibility that one thing (for example an actor) may stand for another (for instance a network)" (Law, 1992). The conference series became the place where the four moments of translation (problematization, interessement, enrolment, and mobilisation of allies) could be played out (Callon, 1986). By participating in the conference series, the two actors, INPE and Prodabel presented cutting-edge research side by side with introductory courses. While INPE presented SPRING, an instrument to implement GIS, Prodabel showcased its project showing future actors in the network that establishing and maintaining a GIS project was possible. Thus they accomplish the first moment of translation, problematization. "They determined a set of actors and defined their identities in such a way as to establish themselves as an obligatory passage point in the network of relationships they were building" (Callon, 1986). It was also instrumental that the two actors, INPE and Prodabel were willing to expand their roles. INPE was only a research institute. It had also designs of having its products (SPRING and remote sensing associated technology) being effectively used by users which would eventually accomplish the final mission of the institute, which is to disseminate knowledge and technology in Brazil. On its side Prodabel, went beyond its original role of deploying services for a local government. Prodabel turned into a center of excellence for GIS and hosts today many masters and Ph.D. scholars, who in turn helped Prodabel perform better its original mission. What happened was that both INPE and Prodabel transcended their original roles and missions. Both went beyond what was originally 
expected from them and maybe the key to explain why Brazil succeeded in the establishment of its SDI. The relationships among the many actors were such that they were encouraged to go beyond their original roles.

Further developments include the creation of a new and more specialized forum for interaction. Led by INPE, Prodabel and other actors a new scientific conference series was established in Brazil in the early 90's. The Geoinfo conference series (www.geoinfo.info) is a landmark of the strength of the research community in GIScience in Brazil. Currently in its $7^{\text {th }}$ version, Geoinfo is also a forum for the meeting of participants in the Brazilian SDI network, more focused on scientific applications.

Although we gave a stronger emphasis in Roger's innovation theory, Actor-Network theory can contribute to the understanding of a successful establishment of a SDI in developing countries. Aspects of the Brazilian network, such as the fact that some actors excelled or surpassed their usual roles, and the development of parallel networks should be further studied in the case exposed here. Other aspects of the Brazilian SDI need also to be examined. For instance, using Rajabifard et al.'s model (Rajabifard, Feeney, \& Williamson, 2002, 2003) will help a further understanding of the role of what they call a SDI hierarchy. In their model, they study the importance of a SDI hierarchy to build understanding and support among participants with different levels and interests. They highlight the importance of cultural and social factors. Another fundamental factor is the establishment of a culture of sharing. In the Brazilian case, the role of INPE as the main provider of information about deforestation highlights what they call the role of global drivers. The centrality of the environmental concerns in Brazil coupled with INPE's pro-active policy to distribute data support some of Rajabifard et al.'s findings. The role of partnerships for data sharing, not explicitly discussed here, also agrees with Rajabifard et al. (Rajabifard et al., 2002, 2003). In short, a complex case such as the development of a SDI in a developing country needs alternative views to be better understood to enable more countries benefiting from successful experiences.

\section{CONCLUSIONS}

In this paper we analyzed the establishment of a SDI in a transitional economy. We used Brazil as a case study. The paper had two basic premises. First, that GIS predates SDI. Before spatial data can be exchanged and made available to a larger public, it 
needs to be organized in spatial databases. Therefore, building a SDI needs an understanding of how GIS technology works. The second premise was that Rogers' diffusion of innovations model helps explaining the Brazilian experience. In Rogers' model, the rate of adoption of an innovation follows a diffusive equation similar to the spreading of an epidemic disease. The cumulative number of adopters of a new technology follows a logistic (S-shaped) curve and therefore, the number of adopters over time follows a normal distribution. Other approaches such as actor-network theory (Latour, 1988) could clarify other important problems involved in GIS/SDI implementation. Because GIS technology is non-neutral, translation-based analysis approaches (such as Actor-Network Theory, Latour, 1988) explained better the roles and importance of each of the main actors in the Brazilian case.

Brazil has been largely successful in setting up qualified institutions that produce and distribute spatial data. We traced these successes to the network of early adopters of GIS in the country. This collaborative network was instrumental in ensuring that such a large and diverse country could benefit from the widespread adoption of spatial information technologies. This collaborative network was successful because its members were able to (1) combine specialized expertise in different segments of spatial information technologies and (2) view knowledge as a public consumption good.

The paper may also provide lessons for other transitional economies with large territories and emerging or established GIS communities. All the groups that comprised the network of innovators in Brazil had a primary background in information technology, rather than mapmaking. GIS and SDI are disruptive technologies which need a new culture to be effectively used. The Brazilian experience shows that it is questionable that institutions with deep-rooted cultures such as most national mapping agencies can be fully successful in setting up SDI without undergoing major internal changes. As a final recommendation, public policies focused on organization of SDI in transitional economies in midsized and large countries should promote the growth of collaborative networks. Governments in transitional economies are encouraged to set up new teams with backgrounds in information technology and substantive depth in spatial concepts and techniques. These teams should be in charge of the building nationwide SDI. 


\section{ACKNOWLEDGEMENTS}

The authors would like to thank and acknowledge the other members of the Brazilian SDI network. For the sake of clarity we omitted many of them here. Some of them are EMPBRAPA, CPqD Telecom, PUC-Rio, UNICAMP, INPA, MPEG, IMPA, UFMG, UFPR, PUC-SP, and CNPq. Gilberto Camara's work is partially funded by CNPq (grants PQ - 300557/19996-5 and 550250/2005-0) and FAPESP (grant 04/110120). Frederico Fonseca's work was partially supported by the National Science Foundation under NSF ITR grant number 0219025 and by the generous support of Penn State's School of Information Sciences and Technology. The authors also would like to acknowledge the many helpful comments from the editors of this special issue and from the anonymous reviewers.

\section{REFERENCES}

Anselin, L. (1989). What's Special about Spatial Data:Alternative Perspectives on Spatial Data Analysis. Santa Barbara, CA: NCGIA Report 89-4.

Arthur, B. (1994). Increasing Returns and Path Dependence in the Economy. Ann Arbor, MI: The University of Michigan Press.

Assad, E.D., \& Sano, E. (Eds.). (1998). Sistemas de informações geográficas: Aplicações na Agricultura (Geographical Information Systems: Agricultural Applications). Brasilia: EMBRAPA.

Borges, K.A.V., \& Sahay, S. (2000). In Learning About GIS Implementation from a Public Sector GIS Experience in Brazil. Paper presented at the IFIP 9.4, Working Group on Social Implications of Computers in Developing Countries, Cape Town, South Africa.

Callon, M. (1986). Some elements of a sociology of translation: domestication of the scallops and the fishermen of St Brieuc Bay. In J. Law (Ed.), Power, action and belief: a new sociology of knowledge? (pp. 196-223). London: Routledge.

Câmara, G., Aguiar, A.P., Escada, M.I., Amaral, S., Carneiro, T., Monteiro, A.M., et al. (2005). Amazon Deforestation Models. Science, 307(15 February 2005), 10431044.

Câmara, G., Casanova, M., Hemerly, A., Magalhães, G., \& Bauzer-Medeiros, C. (1996). Anatomia de Sistemas de Informação Geográfica (Anatomy of Geographical Information Systems), from http://www.dpi.inpe.br/gilberto

Câmara, G., Freitas, U., Souza, R., Casanova, M., Hemerly, A., \& Bauzer-Medeiros, C. (1994). In N. Pissinou \& K. Makki (Eds.), A Model to Cultivate Objects and Manipulate Fields (pp. 20-28). Paper presented at the Second ACM Workshop on Geographic Information Systems, Gaithersburg, MD. ACM Press. 
Câmara, G., Souza, R., Freitas, U., \& Garrido, J. (1996). SPRING: Integrating Remote Sensing and GIS with Object-Oriented Data Modelling. Computers and Graphics, 15(6), 13-22.

Câmara, G., Souza, R., Pedrosa, B., Vinhas, L., Monteiro, A.M., Paiva, J., et al. (2000). In TerraLib: Technology in Support of GIS Innovation. Paper presented at the II Brazilian Symposium on Geoinformatics, GeoInfo2000, São Paulo.

Câmara, G., Sposati, A., Koga, D., Monteiro, A.M., Ramos, F., Druck, S., et al. (2004). Mapping Social Exclusion/Inclusion in Developing Countries: Social Dynamics of São Paulo in the 90's. In M. Goodchild \& D. Janelle (Eds.), Spatially Integrated Social Science: Examples in Best Practice. London: Oxford University Press.

Casanova, M., Camara, G., Davis, C., Vinhas, L., \& Queiroz, G. (Eds.). (2005). Bancos de Dados Geograficos (Spatial Databases). Curitiba: Editora MundoGEO.

Chan, T.O., \& Williamson, I.P. (1999). A Model of the Decision Process for GIS Adoption and Diffusion in a Government Environment. URISA Journal, 11(2), 7-16.

Christensen, C.M. (1997). The innovator's dilemma: when new technologies cause great firms to fail. Boston, Mass.: Harvard Business School Press.

Daratech. (2003). GIS Markets and Opportunities 2003 Survey. Cambridge, MA: Daratech Inc.

Dasgupta, P., \& David, P. (1994). Toward a New Economics of Science. Research Policy, 23, 487-521.

David, P., Mowery, D., \& Steinmueller, W. (1992). Analyzing the Economic Payoffs from Basic Research. Economics of Innovation and New Technology, 2, 73-90.

Davis Jr., C.A. (1993). In URISA (Ed.), Address Base Creation Using Raster-Vector Integration (Vol. 1, pp. 45-54). Paper presented at the URISA 1993 Annual Conference, Atlanta, Georgia. URISA.

Egenhofer, M., \& Frank, A. (1989). Object-Oriented Modeling in GIS: Inheritance and Propagation. In AUTO-CARTO 9, Ninth International Symposium on Computer-Assisted Cartography (pp. 588-598). Baltimore, MD.

Fileto, R., Medeiros, C.B., Liu, L., Pu, C., \& Assad, E.D. (2003). In Using domain ontologies to help track data provenance (pp. 84-98). Paper presented at the XVIII Brazilian Database Symposium, Porto Alegre. SBC.

Fonseca, F. (1993). In URISA (Ed.), GIS for a Two-Million People City in Three Years (Vol. 3, pp. 146-152). Paper presented at the URISA 1993 Annual Conference, Atlanta, Georgia. URISA.

Fonseca, F., Davis, C., \& Camara, G. (2003). Bridging Ontologies and Conceptual Schemas in Geographic Applications Development. Geoinformatica, 7(4), 355378.

Fonseca, F., Egenhofer, M., Agouris, P., \& Câmara, G. (2002). Using Ontologies for Integrated Geographic Information Systems. Transactions in GIS, 6(3), 231-257.

Gates, B., Myhrvold, N., \& Rinearson, P. (1996). The road ahead. New York: Penguin Books. 
Grubler, A. (1998). Technology and Global Change. Cambridge, UK: Cambridge University Press.

Holmes, C., Doyle, A., \& Wilson, M. (2005). In Towards a Free and Open Source (FOSS) Spatial Data Infrastructure. Paper presented at the GSDI -8 - From Pharaohs to Geoinformatics - The Role of SDI's in an Information Society, Cairo, Egypt. GSDI Association.

Landes, D.S. (1999). The Wealth and Poverty of Nations. New York: W. W. Norton \& Co.

Latour, B. (1988). Science in Action: How to Follow Scientists and Engineers Through Society. New York: Harvard University Press.

Law, J. (1992). Notes on the Theory of the Actor-Network: Ordering, Strategy and Heterogeneity. Systems Practice, 5, 379-393.

Magalhaes, G., \& Granemman, E. (2005). A Survey of Geospatial Market in Brazil. São Paulo: GITA Brasil.

Masser, I. (2005). GIS worlds: creating spatial data infrastructures (1st ed.). Redlands, CA: ESRI Press.

McMaster, T., Vidgen, R.T., \& Wastell, D.G. (1997). Technology Transfer: Diffusion or Translation? In T. McMaster (Ed.), Facilitating Technology Transfer through Partnership. London: Chapman \& Hall.

Mowery, D. (Ed.). (1996). The International Computer Software Industry: A Comparative Evolution of Industry Evolution and Structure. New York, NY: Oxford University Press.

Nedovic-Budic, Z. (1998). The Likelihood of Becoming a GIS User. URISA Journal, 10(2).

Nelson, R. (1996). The Sources of Economic Growth. Cambridge, MA: Harvard University Press.

Onsrud, H., Camara, G., Campbell, J., \& Chakravarthy, N.S. (2004). In M.J. Egenhofer, C. Freska \& H.J. Miller (Eds.), Public Commons of Geographic Data: Research and Development Challenges. In, edited by, 223-38. Berlin, 2004. \#3234 (pp. 223-238). Paper presented at the Geographic Information Science, Adelphi, MD. Springer-Verlag.

Rajabifard, A., Feeney, M.-E., \& Williamson, I. (2002). Future Directions for SDI Development. International Journal of Applied Earth Observation and Geoinformation, 4(1), 11-22.

Rajabifard, A., Feeney, M.-E., \& Williamson, I. (2003). Spatial Data Infrastructures: Concept, Nature and SDI Hierarchy. In A. Rajabifard, M.-E. Feeney \& I. Williamson (Eds.), Developing Spatial Data Infrastructures: from Concept to Reality (pp. 17-40). London: Taylor \& Francis.

Ramasubramanian, L. (1999). GIS Implementation in Developing Countries: Learning from Organisational Theory and Reflective Practice. Transactions in GIS, 3(4), 359-380.

Rogers, E. (1995). Diffusion of Innovations (4 ed.). New York: Free Press, 4 ed. 
Ruttan, V. (2001). Technology, Growth and Development. New York: Oxford University Press.

Sahay, S., \& Walsham, G. (1996). Implementation of GIS in India: Organizational Issues and Implications. International Journal of Geographical Information Systems, 10, 385-404.

Shekhar, S., Chawla, S., Ravada, S., Fetterer, A., Liu, X., \& Liu, C.T. (1999). Spatial Databases: Accomplishments and Research Needs. IEEE Transactions on Knowledge and Data Engineering, 11(1), 45-55.

\section{SHORT BIOS}

\subsection{Gilberto Câmara}

\subsection{Frederico Fonseca}

Dr. Fonseca is an assistant professor at the Scholl of Information Sciences and Technology at The Pennsylvania State University since 2001. He works on the area of geographical information systems interoperability providing a theoretical basis for semantic interoperability. With his focus on geographical information systems design, Dr. Fonseca demonstrates how complicated processes can be integrated to the benefit of users. His newly developed concept of ontology-based GIS is highly interdisciplinary as it brings together various research methods from artificial intelligence, software engineering, and GIS. His research on ontologies is currently funded by NSF. Dr. Fonseca has served as a panel reviewer for NSF and as a member of the Advisory Board for the online professional Masters degree program in Geographic Information Systems. Dr. Fonseca is currently teaching a graduate course, Introduction to IST Research, in which he relates his research on Philosophy of Science and Ontologies with specific questions in IS research. Dr. Fonseca also teaches IST 240 Introduction to Computer Languages. For his work in this course, he received recently the George McMurtry Excellence in Teaching and Learning.

\subsection{Antonio Monteiro}




\subsection{Harlan Onsrud}

Professor Onsrud's research focuses on the analysis of legal, ethical, and institutional issues affecting the creation and use of digital databases and the assessment of the social impacts of spatial technologies. He is president of the Global Spatial Data Infrastructure Association (GSDI), past-president of the University Consortium for Geographic Information Science (UCGIS), and past Chair of the U.S. National Committee (USNC) on Data for Science and Technology (CODATA) of the National Research Council. He is a licensed engineer, land surveyor and attorney. Current and past research projects have been funded by the National Science Foundation, the National Geospatial-Intelligence Agency, the Federal Geographic Data Committee, and the U.S. Department of Education. He teaches courses in Information Systems Law, Information Ethics, Cadastral and Land Information Systems, and Research Ethics. 